\title{
Shock-Induced Vibration Suppression of Composite Truss Core Sandwich Plates via Distributed Nonlinear Energy Sinks
}

\section{Wei Zhang}

Beijing University of Technology

\section{Wei Xing Zhang}

BJUT: Beijing University of Technology

\section{Zhong Luo}

Northeastern University

Jianen Chen

Tianjin University of Technology

Dongxing Cao

Beijing University of Technology

XiangYing Guo ( $\nabla$ eagle2008guo@yeah.net)

Beijing University of Technology https://orcid.org/0000-0002-9887-2338

\section{Research Article}

Keywords: Nonlinear energy sinks, Distribution, Shock excitation, Vibration reduction

Posted Date: February 1st, 2022

DOI: https://doi.org/10.21203/rs.3.rs-1288801/v1

License: (c) (1) This work is licensed under a Creative Commons Attribution 4.0 International License. Read Full License 


\title{
Shock-induced vibration suppression of composite truss core sandwich plates via distributed nonlinear energy sinks
}

\author{
Wei Zhang a, Weixing Zhang ${ }^{\mathrm{a}}$, Zhong Luo ${ }^{\mathrm{b}}$, Jianen $\mathrm{Chen}^{\mathrm{c}}$, Dongxing $\mathrm{Cao}^{\mathrm{a}}$, \\ Xiangying $\mathrm{Guo}^{\mathrm{a}^{*}}$ \\ ${ }^{a}$ Beijing Key Laboratory of Nonlinear Vibrations and Strength of Mechanical \\ Structures, Faculty of Materials and Manufacturing, Beijing University of \\ Technology, Beijing, 100124,China \\ ${ }^{b}$ School of Mechanical Engineering and Automation, Northeastern University, \\ Shenyang 110819, China \\ 'School of Mechanical Engineering, Tianjin University of Technology, Tianjin \\ 300384, China \\ Email:guoxy@bjut.edu.cn
}

\begin{abstract}
:
In order to solve the problem of limited installing space and strict additional quality, the effects of distributed nonlinear energy sinks (NES) on a composite truss core sandwich plate are investigated in this paper. Choose five NESs here and inset them in the different places of the sandwich plate to suppress the vibration of the plate, which is excited by a half-wave shock. The coupled dynamic equations of the system are derived by the principle of conservation of energy. Then, numerical simulation are applied to discuss the vibration control performance of the five NESs with different parameters. The distribution of the five NESs are analyzed and the optimal position distributions are obtained. Based on the optimal location, the transient responses of the system are studied. Moreover, five NESs are compared with a single one in different dimensions. Finally, it is found that the selection of parameters have a great impact on the effectiveness of the five NESs. The new distribution way is introduced to improve the suppression effects of the five NESs in the sandwich plates.
\end{abstract}

Keywords: Nonlinear energy sinks; Distribution; Shock excitation; Vibration reduction 


\section{Introduction}

Sandwich structures are usually composed of two stiff face skins and thicker core material, such as Kagome, tetrahedral and pyramidal cores. They have a broad application prospect in the engineering field because of their excellent properties, such as high specific strength, high specific stiffness, energy absorption, thermal conductivity and so on [1-4].

In recent years, many scholars have done a lot on sandwich structures to grasp their characteristics more. Zhang et al.[5] investigated the global and chaotic dynamics of sandwich plates with truss core. Wang et al.[6] studied acoustic transmission of laminated composite sandwich structures with pyramidal truss cores. Zangana et al.[7] analyzed the dynamic characteristics of composite corrugated core sandwich structures subjected to low-velocity shocks. Li et al.[8] theoretically and experimentally investigated the natural frequencies and the vibration modes of pyramidal truss core sandwich plates with local damage. Xiong et al.[9] analyzed the structural performance of composite sandwich panels under direct shear and three-point bending loads. Wang et al.[10] investigated the mechanical behaviors of composite sandwich plates with 2-D lattice truss cores by out-of-plane compression, shear and three-point bending tests. Huang et al.[11] analyzed the dynamic responses and failures of composite lattice core sandwich beams under impulsive loading. In addition, considering the special core layer of sandwich structures, some scholars investigated its internal space availability, such as, Yin et al. [12] present damping performance and energy absorption capacity of silicone rubber-filled sandwich structures. Zhang et al.[13] studied dynamic responses of pyramidal lattice core sandwich panels, improving the energy absorption and low velocity shock resistances by filling the polyurethane foams. Chen et al. [14] put forward the aerogel-filled sandwich panels to provide both mechanical supports and thermal insulation.

Meanwhile, the vibration control are another important research problem for the sandwich structures, specifically in condition of strong reliability and high vibration suppression requisition. Li et al. [15] analyzed the vibration suppression effects of the active control method on the vibration responses of lattice sandwich beams by the piezoelectric actuator/sensor pairs. Song et al. [16] analyzed the flutter suppression of the lattice sandwich beams by means of active vibration control. Chai et al. [17] 
investigated the nonlinear responses and vibration control of sandwich plates with different cores.

As one of the popular way to suppress the harmful vibration, nonlinear energy sink (NES) have the characteristics of small additional mass, wider vibration suppression frequency band, and targeted energy transfer [18-22]. Moslemi et al. [23] analyzed the effects of NES on dynamic responses for axially moving beams. Liu et al. [24] investigated the vibration suppression efficiency of NES with geometrically nonlinear damping. Taghipouret al. [25] researched the steady-state dynamic responses of a primary structure with cubic nonlinear stiffness connected with the NES under harmonic excitations. Fang et al.[26] analyzed the vibration suppression of bistable NES on transient responses of a Bernoulli-Euler beam and targeted energy transfer of the system. Zang et al.[27] discussed the influence of lever-type NES on dynamic responses of structures subjected to harmonic excitation. Chen et al.[28] obtained the better vibration reduction by comparing parallel NESs with a single one. They also present the parallel NES could eliminate the high branch responses of the system due to nonlinear terms. Tian et al.[29] attached NES to a hypersonic 3-D wing to reduce aeroelastic responses of a wing. Li et al.[30] proposed a symmetric single-sided vibro-impact NES to suppress the vibration of cantilever beams. Zhang et al.[31] mitigated the vibration of composite laminated plates using an NES, which subjected to high speed wind loadings. Yao et al.[32] discussed the effects of a grounded NES on the lateral vibration of rotor systems. Zhang et al.[33, 34] utilized a NES to suppress the shock-induced vibration of an axially moving beam.

From the above references, the reported researches are mainly on the dynamical characteristic for single NES. Only a few researches have paid attention on the distributed NES, which is a good way to expand the application ranges of NES absorbers. This paper present the vibration control performance of multiple NES absorbers on composite truss core sandwich plates with shock loading. Firstly, the dynamical equations of motion for a composite truss core sandwich plate are built with five inside distributed NESs. These NESs are embedded in the core of the sandwich plate, where one NES is in the center of the composite plate and the other four NESs are symmetrically placed on four sides of the plate. Then, the influence of position distribution of the NESs on the energy dissipation capacity are discussed. Based on the criteria of the optimal energy dissipation position, it is analyzed with the transient responses for the feasibility of five NESs and the difference of vibration 
reductions on the first three modes of the plate. In addition, the vibration control performance of single NES and the distributed five NESs are compared to show the suppression advantages of the five NESs with the same structure. Finally, the effects of different parameters for the five NESs on energy dissipation are investigated to improve the performance of the NESs.

\section{Equation of motion}

Consider a composite truss core sandwich plate subjected to a shock load $F$ as Fig. 1(a). The sandwich plate is composed of three layers, where the upper and lower face sheets are made of carbon fibers and the middle core is arranged by pyramidal truss core. The five NESs are named as $N_{1}, N_{2}, N_{3}, N_{4}$, and $N_{5}$, respectively, which are embedded in five different truss core units. The pyramidal truss core unit with the NES is shown as Fig. 1(b). The mechanical model of the NES gives in Fig. 1(c). The Cartesian coordinate system is built on the central surface of the plate, and $u, v$ and $w$ represent the displacements of any point of the plate in the $x, y$ and $z$ directions, respectively. The shock load $F$ acts on the position $\left(P_{1}, P_{2}\right)$. Moreover, the symbolic representation of structural parameters are shown in Table 1.

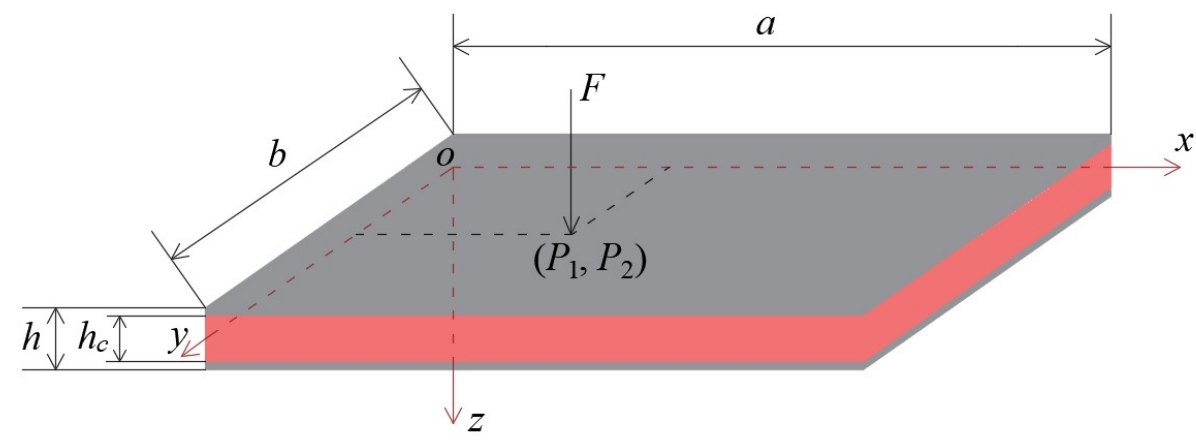

(a)

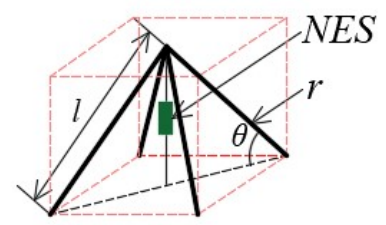

(b)

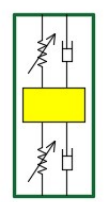

(c)

Fig. 1 System model: (a) composite truss core sandwich plate excited by shock load ; (b) the pyramidal truss core unit with the NES; (c) the mechanical model of the NES. 
Table 1 The symbolic representation of structural parameters

\begin{tabular}{ll|}
\hline Structural parameters & Symbols \\
\hline Plate length & $a$ \\
Plate width & $b$ \\
Plate height & $h$ \\
Height of core layer & $h_{c}$ \\
Length of truss core unit & $l$ \\
Radius of truss core unit & $r$ \\
Inclination angle & $\theta$ \\
\hline
\end{tabular}

Based on Allen's theory[35], the following assumptions are given as

(1) The thickness of the truss core sandwich plate remains constant during deformation;

(2) Bending deformation only exists in the thin face sheets and shear one happens in the thick truss core of the plate;

(3) The deflections of the whole plate are continuous.

Then, the equivalent density is expressed as

$$
\rho_{c}=\frac{2 \pi \rho}{\cos ^{2} \theta \sin \theta}\left(\frac{r}{l}\right)^{2}
$$

The shear modulus of the truss core are written as

$$
G_{13 c}=G_{23 c}=\pi \sin \theta\left(\frac{r}{l}\right)^{2} E_{1}
$$

The thin face sheets are made of carbon fiber composite, which are laid in five layers as $0 / 90 / 0 / 90 / 0$. The stress-strain relations for the composite material can be expressed as follows

$$
\left\{\begin{array}{c}
\sigma_{x x} \\
\sigma_{y y} \\
\sigma_{x y}
\end{array}\right\}=\left\{\begin{array}{ccc}
\bar{Q}_{11} & \bar{Q}_{12} & 0 \\
\bar{Q}_{21} & \bar{Q}_{22} & 0 \\
0 & 0 & \bar{Q}_{66}
\end{array}\right\}\left\{\begin{array}{c}
\varepsilon_{x x} \\
\varepsilon_{y y} \\
\varepsilon_{x y}
\end{array}\right\}
$$

where the equivalent modulus $\bar{Q}_{i j}$ can be expressed as

$$
\begin{aligned}
& \bar{Q}_{11}=Q_{11} \cos ^{4} \alpha+2\left(Q_{12}+2 Q_{66}\right) \sin ^{2} \alpha \cos ^{2} \alpha+Q_{22} \sin \alpha \\
& \bar{Q}_{12}=\left(Q_{11}+Q_{22}-4 Q_{66}\right) \sin ^{2} \alpha \cos ^{2} \alpha+Q_{12}\left(\sin ^{4} \alpha+\cos ^{4} \alpha\right) \\
& \bar{Q}_{22}=Q_{11} \sin ^{4} \alpha+2\left(Q_{12}+2 Q_{66}\right) \sin ^{2} \alpha \cos ^{2} \alpha+Q_{22} \cos ^{4} \alpha \\
& \bar{Q}_{66}=\left(Q_{11}+Q_{22}-2 Q_{12}-2 Q_{66}\right) \sin ^{2} \alpha \cos ^{2} \alpha+Q_{66}\left(\sin ^{4} \alpha+\cos ^{4} \alpha\right)
\end{aligned}
$$


Here, $Q_{i j}$ is the elastic constant and $\alpha$ is the stacking angle of face sheet.

Based on the mechanical condition of the plate, first-order shear deformation theory[36] is applied here to express the displacement fields of the structure as

$$
\begin{aligned}
& u(x, y, t)=z \Psi_{x}(x, y, t) \\
& v(x, y, t)=z \Psi_{y}(x, y, t) \\
& w(x, y, t)=w_{0}(x, y, t)
\end{aligned}
$$

where $\Psi_{x}$ and $\Psi_{y}$ are the rotations of the transverse normal about the $y$ - and $x$-axes, respectively.

The relationship of strain and displacement can be expressed as

$$
\begin{aligned}
& \varepsilon_{x x}=\frac{1}{2}\left(\frac{\partial w_{0}}{\partial x}\right)^{2}+z \frac{\partial \Psi_{x}}{\partial x}, \varepsilon_{y y}=\frac{1}{2}\left(\frac{\partial w_{0}}{\partial y}\right)^{2}+z \frac{\partial \Psi_{y}}{\partial y}, \varepsilon_{z z}=0 \\
& \gamma_{x y}=\frac{\partial w_{0}}{\partial x} \frac{\partial w_{0}}{\partial y}+z\left(\frac{\partial \Psi_{x}}{\partial y}+\frac{\partial \Psi_{y}}{\partial x}\right), \gamma_{x z}=\frac{\partial w_{0}}{\partial x}+\Psi_{x}, \gamma_{y z}=\frac{\partial w_{0}}{\partial y}+\Psi_{y} .
\end{aligned}
$$

Applying the Hamilton's principle, the motion equations of the sandwich plate coupled with five NESs can be derived as

$$
\begin{aligned}
& D_{11} \frac{\partial^{2} \Psi_{x}}{\partial x^{2}}+D_{12} \frac{\partial^{2} \Psi_{y}}{\partial x \partial y}+D_{66}\left(\frac{\partial^{2} \Psi_{x}}{\partial y^{2}}+\frac{\partial^{2} \Psi_{y}}{\partial x \partial y}\right)-\kappa A_{55}\left(\frac{\partial w_{0}}{\partial x}+\Psi_{x}\right)=I_{2} \ddot{\Psi}_{x} \\
& D_{22} \frac{\partial^{2} \Psi_{y}}{\partial y^{2}}+D_{12} \frac{\partial^{2} \Psi_{x}}{\partial x \partial y}+D_{66}\left(\frac{\partial^{2} \Psi_{y}}{\partial y^{2}}+\frac{\partial^{2} \Psi_{x}}{\partial x \partial y}\right)-\kappa A_{44}\left(\frac{\partial w_{0}}{\partial y}+\Psi_{y}\right)=I_{2} \ddot{\Psi}_{y} \\
& \kappa A_{55}\left(\frac{\partial w_{0}^{2}}{\partial x^{2}}+\frac{\partial \Psi_{x}}{\partial x}\right)+\kappa A_{44}\left(\frac{\partial w_{0}^{2}}{\partial y^{2}}+\frac{\partial \Psi_{y}}{\partial y}\right)+F \delta\left(x-P_{1}, y-P_{2}\right)-\mu_{0} \dot{w}_{0} \\
& +\sum_{i=1}^{5}\left[K_{i}\left(w_{n i}-w_{p}\right)^{3}+\mu_{i}\left(\dot{w}_{n i}-\dot{w}_{p}\right)\right] \delta\left(x-A_{i}, y-B_{i}\right)=I_{0} \ddot{w}_{0} \\
& m_{i} \ddot{w}_{n i}+K_{i}\left(w_{n i}-w_{p}\right)^{3}+\mu_{i}\left(\dot{w}_{n i}-\dot{w}_{p}\right)=0(i=1,2,3,4,5)
\end{aligned}
$$

where,

$$
\begin{aligned}
& D_{i j}=D_{i j 1}+D_{i j 3}(i, j=1,2,6), D_{i j 1}=\int_{-\frac{h}{2}}^{-\frac{h_{c}}{2}} \bar{Q}_{i j} z^{2} d z, D_{i j 3}=\int_{\frac{h_{c}}{2}}^{\frac{h}{2}} \bar{Q}_{i j} z^{2} d z, A_{44}=\int_{-\frac{h_{c}}{2}}^{\frac{h_{c}}{2}} G_{13 c} d z, \\
& A_{55}=\int_{-\frac{h_{c}}{2}}^{\frac{h_{c}}{2}} G_{23 c} d z, I_{i}=\sum_{k=1}^{N} \int_{z_{k}}^{z_{k+1}} \rho^{(k)}(z)^{i} d z(i=0,2), w_{p}=w_{0}\left(A_{i}, B_{i}, t\right) \quad(i=1,2,3,4,5),
\end{aligned}
$$
here, $\left(A_{i}, B_{i}\right)$ represent the locations of five NESs in the plate. $m_{i} 、 \mu_{i} 、 K_{i} 、 w_{n i}$ are the mass, damping, stiffness, and displacements of the NESs, respectively. $\mu_{0}$ is the damping of the sandwich plate. $\kappa$ is the shear correction coefficient. $A_{44}$ and $A_{55}$ are the extensional stiffness. $D_{i j}$ is the bending stiffness. The rotational inertia terms in equation (7) can be ignored for the small values. 
In order to obtain the dimensionless dynamic equation, the following transformation are introduced,

$$
\begin{aligned}
& \bar{w}_{0}=\frac{w_{0}}{h}, \quad \bar{w}_{n i}=\frac{w_{n i}}{h}, \quad \bar{\Psi}_{x}=\Psi_{x}, \bar{\Psi}_{y}=\Psi_{y}, \bar{x}=\frac{x}{a}, \bar{y}=\frac{y}{b}, \bar{F}=\frac{a^{2} b^{2}}{E_{1} h^{4}} F, \\
& \bar{\mu}=\frac{a b}{h^{2}}\left(\frac{1}{\rho E_{1}}\right)^{\frac{1}{2}} \mu, \bar{t}=\frac{h}{a b}\left(\frac{E_{1}}{\rho}\right)^{\frac{1}{2}} t, \bar{\Omega}=\frac{a b}{h}\left(\frac{\rho}{E_{1}}\right)^{\frac{1}{2}} \Omega, \quad \bar{A}_{i j}=\frac{(a b)^{\frac{1}{2}}}{E_{1} h^{2}} A_{i j}, \\
& \bar{D}_{i j}=\frac{(a b)^{\frac{1}{2}}}{E_{1} h^{h}} D_{i j}, \quad \bar{K}=\frac{a^{2} b^{2}}{E_{1} h} K, \quad \bar{m}=\frac{1}{(a b)^{\frac{1}{2}}} m, \bar{I}_{0}=\frac{1}{(a b)^{\frac{i+1}{2}} \rho} I_{0} .
\end{aligned}
$$

For convenience, the "-" on the dimensionless symbols are ignored. Substituting equation (8) into equation (7), the dimensionless dynamic equations of the system can be written as:

$$
\begin{aligned}
& q_{11} \frac{\partial^{2} \Psi_{x}}{\partial x^{2}}+q_{12} \frac{\partial^{2} \Psi_{y}}{\partial x \partial y}+q_{13} \frac{\partial^{2} \Psi_{x}}{\partial y^{2}}-q_{14} \frac{\partial w_{0}}{\partial x}-q_{15} \Psi_{x}=0 \\
& q_{21} \frac{\partial^{2} \Psi_{y}}{\partial y^{2}}+q_{22} \frac{\partial^{2} \Psi_{x}}{\partial x \partial y}+q_{23} \frac{\partial^{2} \Psi_{y}}{\partial y^{2}}-q_{24} \frac{\partial w_{0}}{\partial y}-q_{25} \Psi_{y}=0 \\
& \ddot{w}_{0}+\gamma_{0} \dot{w}_{0}-q_{31} \frac{\partial w_{0}^{2}}{\partial x^{2}}-q_{32} \frac{\partial \Psi_{x}}{\partial x}-q_{33} \frac{\partial w_{0}^{2}}{\partial y^{2}}-q_{34} \frac{\partial \Psi_{y}}{\partial y} \\
& +\sum_{i=1}^{5}\left[k_{i}\left(w_{p}-w_{n i}\right)^{3}+\gamma_{i}\left(\dot{w}_{p}-\dot{w}_{n i}\right)\right] \delta\left(x-a_{i}, y-b_{i}\right)=F \delta\left(x-p_{1}, x-p_{2}\right) \\
& \varepsilon_{i} \ddot{w}_{n i}+k_{i}\left(w_{n i}-w_{p}\right)^{3}+\gamma_{i}\left(\dot{w}_{n i}-\dot{w}_{p}\right)=0(i=1,2,3,4,5)
\end{aligned}
$$

where,

$$
\begin{aligned}
& q_{11}=\frac{h^{2}}{a^{2}} D_{11}, \quad q_{12}=\frac{h^{2}}{a b}\left(D_{12}+D_{66}\right), \quad q_{13}=\frac{h^{2}}{b^{2}} D_{66}, \quad q_{14}=\frac{\kappa h}{a} A_{55}, \quad q_{15}=\kappa A_{55}, \quad q_{21}=\frac{h^{2}}{b^{2}} D_{22}, \\
& q_{22}=\frac{h^{2}}{a b}\left(D_{12}+D_{66}\right), \quad q_{23}=\frac{h^{2}}{a^{2}} D_{66}, \quad q_{24}=\frac{\kappa h}{b} A_{44}, \quad q_{25}=\kappa A_{44}, \quad q_{31}=\frac{\kappa b A_{55}}{a I_{0}}, \quad q_{32}=\frac{\kappa b A_{55}}{h I_{0}}, \\
& q_{33}=\frac{\kappa a A_{44}}{b I_{0}}, \quad q_{34}=\frac{\kappa a A_{44}}{h I_{0}}, \quad \gamma_{0}=\frac{h \mu_{0}}{(a b)^{\frac{1}{2}} I_{0}}, \quad \gamma_{i}=\frac{h \mu_{i}}{(a b)^{\frac{1}{2}} I_{0}}, \quad k_{i}=\frac{h K_{i}}{(a b)^{\frac{1}{2}} I_{0}}, \Gamma=\frac{h F}{(a b)^{\frac{1}{2}} I_{0}}, \\
& \varepsilon_{i}=\frac{m_{i}}{I_{0}}, \quad p_{1}=\frac{P_{1}}{a}, \quad p_{2}=\frac{P_{2}}{b}, \quad a_{i}=\frac{A_{i}}{a}, \quad b_{i}=\frac{B_{i}}{b} .
\end{aligned}
$$

Based on the simply supported boundary conditions of the composite truss core sandwich plate, $\Psi_{x} 、 \Psi_{y}$ and $w_{0}$ can be expressed as

$$
\begin{aligned}
& \Psi_{x}=\sum_{n=1}^{\infty} \sum_{m=1}^{\infty} 2 x_{m n}(t) \cos m \pi x \sin n \pi y \\
& \Psi_{y}=\sum_{n=1}^{\infty} \sum_{m=1}^{\infty} 2 y_{m n}(t) \sin m \pi x \cos n \pi y \\
& w_{0}=\sum_{n=1}^{\infty} \sum_{m=1}^{\infty} 2 w_{m n}(t) \sin m \pi x \sin n \pi y
\end{aligned}
$$


Since the harmful vibration of low-frequency and large amplitude are the main cause for structural damage, here, we focus on the response absorption of the first three natural frequencies for the plate.Using the Galerkin method, the dimensionless dynamic equations of the motion for the coupled system can be obtained as follows.

$$
\begin{aligned}
& \ddot{w}_{1}+\gamma_{0} \dot{w}_{1}+\omega_{1}^{2} w_{1}+\sum_{i=1}^{5} k_{i}\left[w_{1} q_{1}\left(a_{i}, b_{i}\right)+w_{2} q_{2}\left(a_{i}, b_{i}\right)+w_{3} q_{3}\left(a_{i}, b_{i}\right)-w_{n i}\right]^{3} q_{1}\left(a_{i}, b_{i}\right) \\
& +\sum_{i=1}^{5} \gamma_{i}\left[\dot{w}_{1} q_{1}\left(a_{i}, b_{i}\right)+\dot{w}_{2} q_{2}\left(a_{i}, b_{i}\right)+\dot{w}_{3} q_{3}\left(a_{i}, b_{i}\right)-\dot{w}_{n i}\right] q_{1}\left(a_{i}, b_{i}\right)=\Gamma q_{1}\left(p_{1}, p_{2}\right) \\
& \ddot{w}_{2}+\gamma_{0} \dot{w}_{2}+\omega_{2}^{2} w_{2}+\sum_{i=1}^{5} k_{i}\left[w_{1} q_{1}\left(a_{i}, b_{i}\right)+w_{2} q_{2}\left(a_{i}, b_{i}\right)+w_{3} q_{3}\left(a_{i}, b_{i}\right)-w_{n i}\right]^{3} q_{2}\left(a_{i}, b_{i}\right) \\
& +\sum_{i=1}^{5} \gamma_{i}\left[\dot{w}_{1} q_{1}\left(a_{i}, b_{i}\right)+\dot{w}_{2} q_{2}\left(a_{i}, b_{i}\right)+\dot{w}_{3} q_{3}\left(a_{i}, b_{i}\right)-\dot{w}_{n i}\right] q_{2}\left(a_{i}, b_{i}\right)=\Gamma q_{2}\left(p_{1}, p_{2}\right) \\
& \ddot{w}_{3}+\gamma_{0} \dot{w}_{3}+\omega_{3}^{2} w_{3}+\sum_{i=1}^{5} k_{i}\left[w_{1} q_{1}\left(a_{i}, b_{i}\right)+w_{2} q_{2}\left(a_{i}, b_{i}\right)+w_{3} q_{3}\left(a_{i}, b_{i}\right)-w_{n i}\right]^{3} q_{3}\left(a_{i}, b_{i}\right) \\
& +\sum_{i=1}^{5} \gamma_{i}\left[\dot{w}_{1} q_{1}\left(a_{i}, b_{i}\right)+\dot{w}_{2} q_{2}\left(a_{i}, b_{i}\right)+\dot{w}_{3} q_{3}\left(a_{i}, b_{i}\right)-\dot{w}_{n i}\right] q_{3}\left(a_{i}, b_{i}\right)=\Gamma q_{3}\left(p_{1}, p_{2}\right) \\
& \ddot{E}_{i} \ddot{w}_{n i}+k_{i}\left[w_{n i}-w_{1} q_{1}\left(a_{i}, b_{i}\right)-w_{2} q_{2}\left(a_{i}, b_{i}\right)-w_{3} q_{3}\left(a_{i}, b_{i}\right)\right]^{3} \\
& +\gamma_{i}\left[\dot{w}_{n i}-\dot{w}_{1} q_{1}\left(a_{i}, b_{i}\right)-\dot{w}_{2} q_{2}\left(a_{i}, b_{i}\right)-\dot{w}_{3} q_{3}\left(a_{i}, b_{i}\right)\right]=0(i=1,2,3,4,5)
\end{aligned}
$$

where $\omega_{1}, \omega_{2}$ and $\omega_{3}$ are the first three natural frequencies of the sandwich plate. $q_{1}(x, y), q_{2}(x, y)$ and $q_{3}(x, y)$ are the components acting on the first three modes.

\section{Overall performances for the five NESs}

Numerical simulation methods are applied here to analyze the overall performance of the five NESs absorber. To be clear, the units of the sandwich plate are numbered sequentially as shown in Fig. 2. The locations of the five NESs are circled in red in Fig. 2, where $N_{1}$ corresponds to the coordinate point $(0.5,0.5)$, and $N_{2}, N_{3}, N_{4}$ and $N_{5}$ are symmetrically distributed around. In the following study, let $N_{2}, N_{3}, N_{4}$ and $N_{5}$ change synchronously to keep their symmetry of the center, and the position of the four NESs can be adjusted by changing the position of $N_{2}$ coordinate $\left(a_{2}, b_{2}\right)$.

The physical and geometrical parameters of the sandwich plate used in this paper are shown in Table 2. In addition, the thickness of each lamina is $0.12 \mathrm{~mm}$.

The shock load $\Gamma$ is in the form of a half-sine pulse as

$$
\Gamma=\left\{\begin{array}{cl}
f \sin (2 \pi t / T) & 0 \leq t \leq T / 2 \\
0 & T>T / 2
\end{array} \quad(T=0.4 / \pi)\right.
$$




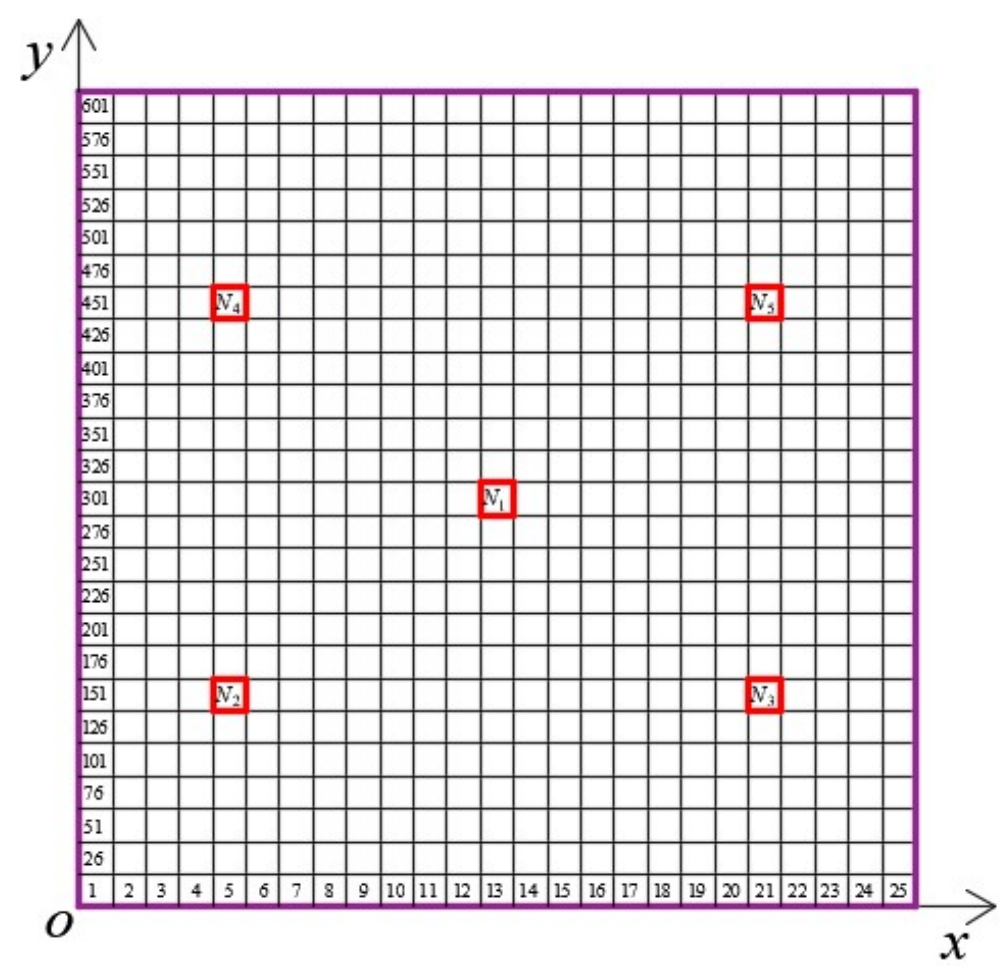

Fig. 2 Units in two-dimensional coordinate system

Table 2 Geometry and material property parameters of the sandwich plate

\begin{tabular}{ll} 
Items & Values \\
\hline Density & $\rho=1570 \mathrm{~kg} / \mathrm{m}^{3}$ \\
& $v_{12}=0.25$ \\
& $v_{13}=0.25$ \\
& $v_{23}=0.38$ \\
& $E_{1}=1.32 \times 10^{5} \mathrm{MPa}$ \\
& $E_{2}=1.03 \times 10^{4} \mathrm{MPa}$ \\
& $E_{3}=1.03 \times 10^{4} \mathrm{MPa}$ \\
Elastic moduli & $G_{13}=6.5 \times 10^{3} \mathrm{MPa}$ \\
& $G_{12}=6.5 \times 10^{3} \mathrm{MPa}$ \\
Shear moduli & $G_{23}=3.91 \times 10^{3} \mathrm{MPa}$ \\
& $a=1 \mathrm{~m}$ \\
Plate length & $b=1 \mathrm{~m}$ \\
Plate width & $l=0.04 \mathrm{~m}$ \\
Rod length & $\theta=\pi / 4$ \\
Inclination angle & $r=1 \times 10^{-3} \mathrm{~m}$ \\
Rod radius & \\
&
\end{tabular}




\subsection{Determination of the optimal position of five NESs}

The optimal position of vibration suppression for the five NESs are discussed firstly. Generally speaking, it is agreed that the vibration suppression is effective when the responses of the controlled system can be reduced to $5 \%$ of the initial amplitude. We also use this criterion to test the vibration absorption capacity of the five NESs. Let the parameters of the five NESs be equal, which include stiffness, damping and mass. Moreover, the specific parameters are set to $\varepsilon_{i}=0.02, \gamma_{i}=0.05, k_{i}=800$. The following study is done in three steps. First one, suppose the shock force act on the point $\left(p_{1}=0.35, p_{2}=0.35\right)$ and its amplitudes be $f=1, f=3$ and $f=5$, respectively. Based on the numbering sequence in Fig 2, $N_{2}$ is placed in the different number unit in sequence from small to large.

The energy dissipation ratio is introduced to analyze the overall efficiency of the five NESs with different distribution. The related equation is written as

$$
\eta=\frac{\sum_{i=1}^{5} \gamma_{i} \int_{0}^{t}\left[\dot{w}_{1} q_{1}\left(a_{i}, b_{i}\right)+\dot{w}_{2} q_{2}\left(a_{i}, b_{i}\right)+\dot{w}_{3} q_{3}\left(a_{i}, b_{i}\right)-\dot{w}_{n i}\right] d \tau}{\int_{0}^{t} \Gamma\left[\dot{w}_{1} q_{1}\left(p_{1}, p_{2}\right)+\dot{w}_{2} q_{2}\left(p_{1}, p_{2}\right)+\dot{w}_{3} q_{3}\left(p_{1}, p_{2}\right)\right] d \tau}
$$

Fig. 3 shows the energy dissipation ratios of five NESs at different positions, where different colors indicate the energy dissipation ratios of the NESs. It can be found that there exist optimal energy dissipation areas for the five NESs. No matter how big the amplitude of the shock force, the optimal area distribution for vibration suppression are similar with each other. Therefore, the optimal vibration suppression area of the five NESs can be selected as a rough range, which are surrounded by the black boxes in Fig. 4. The corner coordinates of these black boxes are marked as $S_{1}$, $S_{2}, S_{3}$ and $S_{4}$, which are

$$
\begin{aligned}
& S_{1}=\{(0.2,0.2),(0.4,0.2),(0.2,0.4),(0.4,0.4)\}, \\
& S_{2}=\{(0.6,0.2),(0.8,0.2),(0.6,0.4),(0.8,0.4)\}, \\
& S_{3}=\{(0.2,0.6),(0.4,0.6),(0.2,0.8),(0.4,0.8)\}, \\
& S_{4}=\{(0.6,0.6),(0.8,0.6),(0.6,0.8),(0.8,0.8)\} .
\end{aligned}
$$

Second step, chose two different locations of the five NESs as an example, where one is in the optimal position range as $\left(a_{2}=0.3, b_{2}=0.3\right)$ and the other is out of this range as $\left(a_{2}=0.18, b_{2}=0.18\right)$. Meanwhile, keep the dimensionless shock amplitude $f$ be 1 , and then the transient responses of the sandwich plate without and with the five NESs in two different positions are shown in Fig. 4, in which the vertical coordinate 
$w$ is the sum amplitudes of the first three modes. It is easy to see that the effective suppression time need to be 123.1 without NESs and only 9.4 and 21.5 for the five NESs in $\left(a_{2}=0.3, b_{2}=0.3\right)$ and $\left(a_{2}=0.18, b_{2}=0.18\right)$, respectively. Therefore, the layout for the five NESs in Fig. 4(a) is much better than that in Fig. 4(b) and the optimal position can make the the five NESs work efficiently.
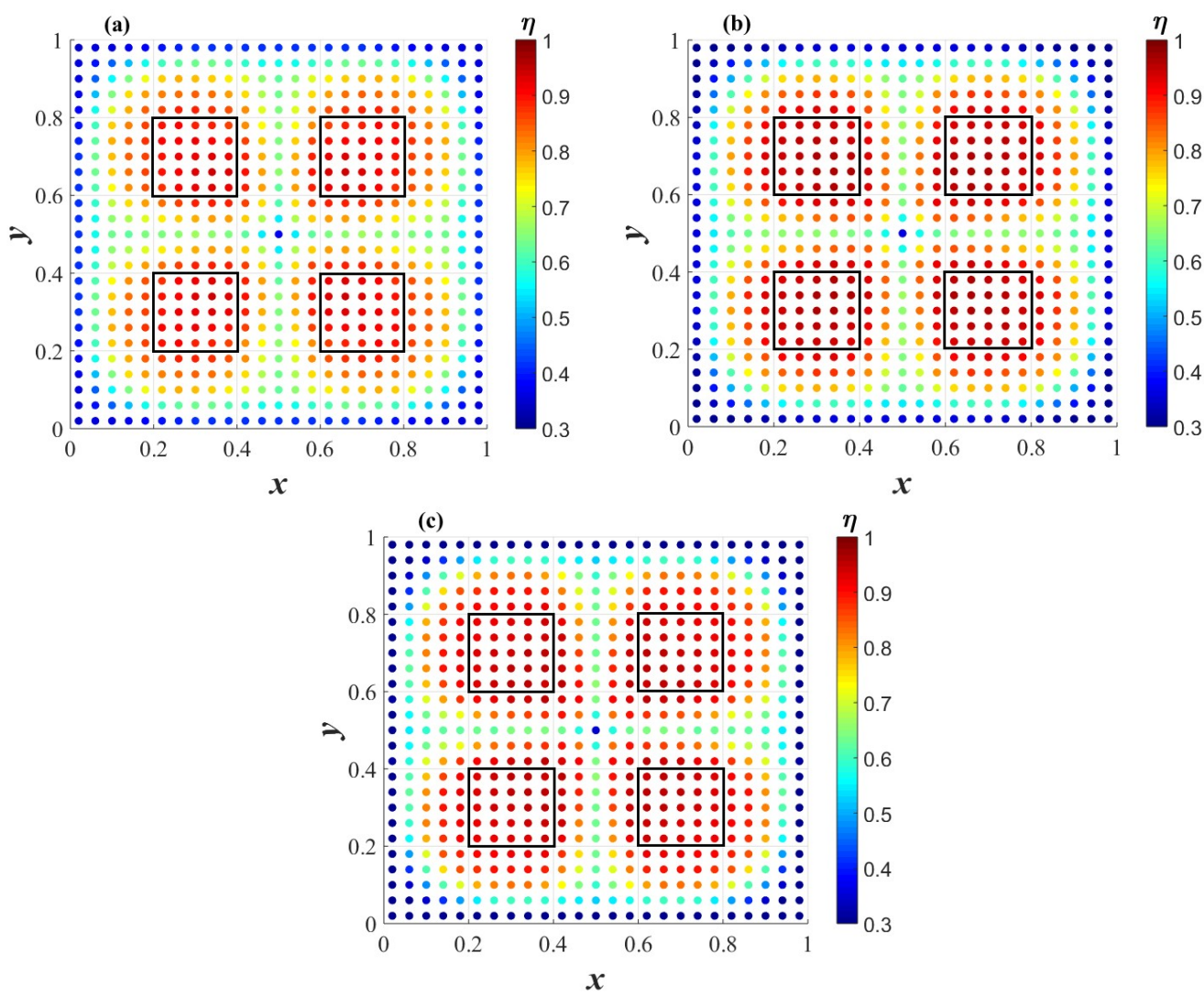

Fig. 3 Energy dissipation ratios of five NESs at different positions under different excitation amplitudes: (a) $f=1$; (b) $f=3$; (c) $f=5$
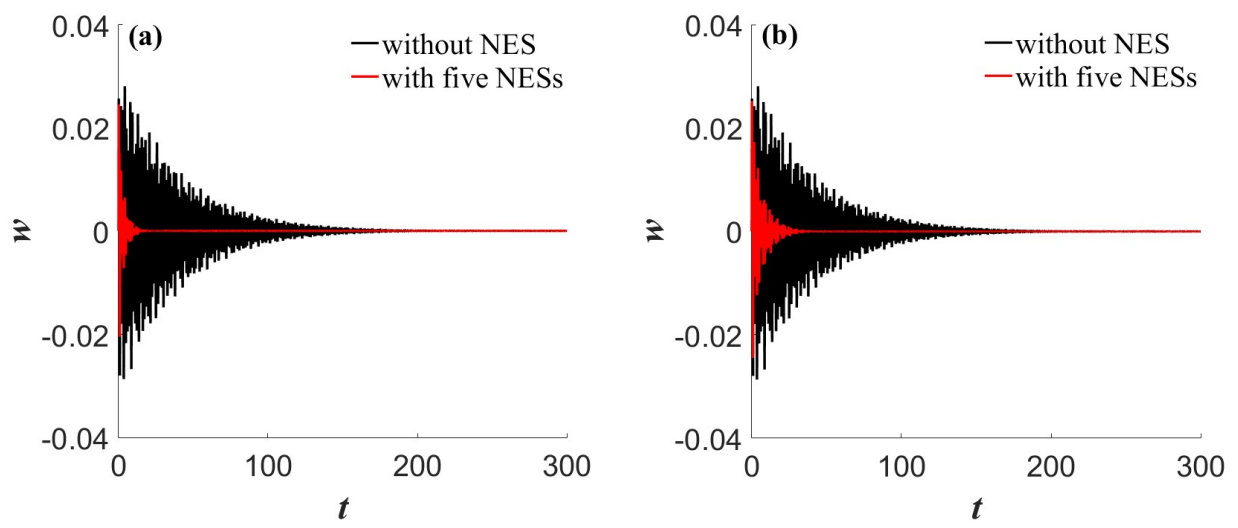

Fig. 4 Comparison of vibration reduction performance of five NESs under different locations: (a) the responses when $\left(a_{2}=0.3, b_{2}=0.3\right)$; (b) the responses when $\left(a_{2}=0.18, b_{2}=0.18\right)$ 
Third step, keeping the shock amplitude $f=5$ and changing the location of shock. Fig. 5 shows the energy dissipation ratios of the five NESs with the shock force on $\left(p_{1}=0.5, p_{2}=0.5\right)$ and $\left(p_{1}=0.5, p_{2}=0.3\right)$. From Figs. $5(\mathrm{a}), 5(\mathrm{~b})$ and $3(\mathrm{c})$, it is found that the optimal location of the five NESs will change with the varied position of the loading. Thus, set the shock force be at the position $\left(p_{1}=0.35, p_{2}=0.35\right)$ and the five NESs be at $\left(a_{2}=0.3, b_{2}=0.38\right)$ for the following research.
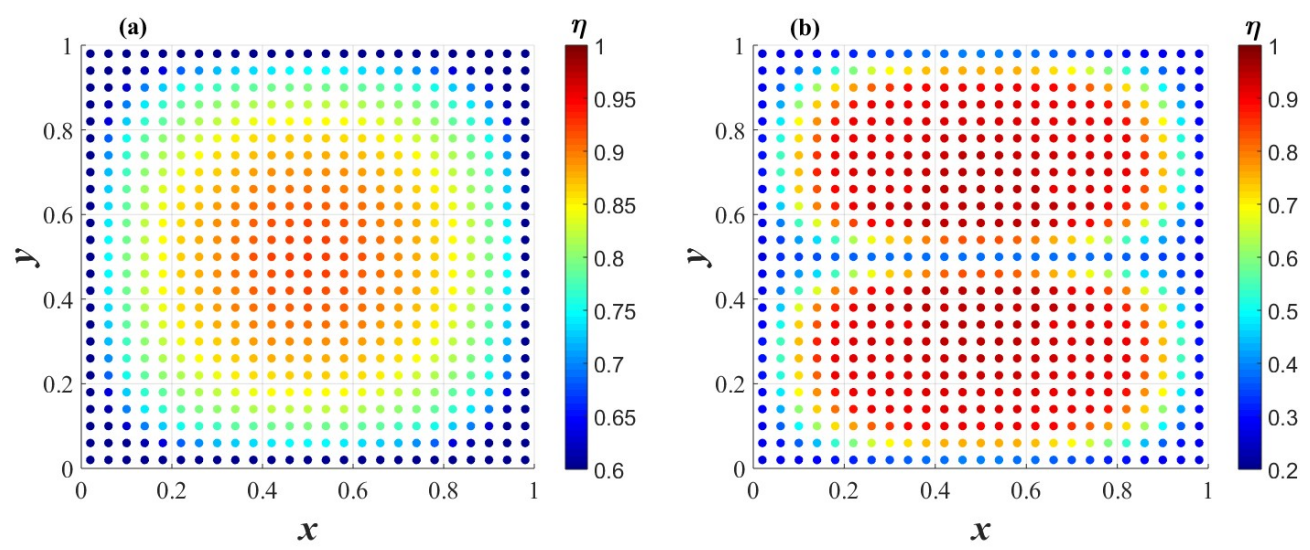

Fig. 5 The energy dissipation ratios of five NESs at different positions when $f=5$ :

(a) $\left(p_{1}=0.5, p_{2}=0.5\right)$; (b) $\left(p_{1}=0.5, p_{2}=0.3\right)$

\subsection{Research on transient responses based on the optimal position}

Here, two different amplitudes of the load are considered, including $f=5$ and $f=10$. The relative displacements between the NESs and the sandwich plate are shown in Figs. 6 and 7, respectively. With the increase of force, the duration of relative displacements between the sandwich plate and the NESs are longer. Due to different positions, the maximum relative displacement between each substructure and the sandwich plate is different, but they are in a reasonable range, i.e. $-h_{c} / 2 h<w_{r i}<h_{c} / 2 h(i=1,2,3,4,5)$.
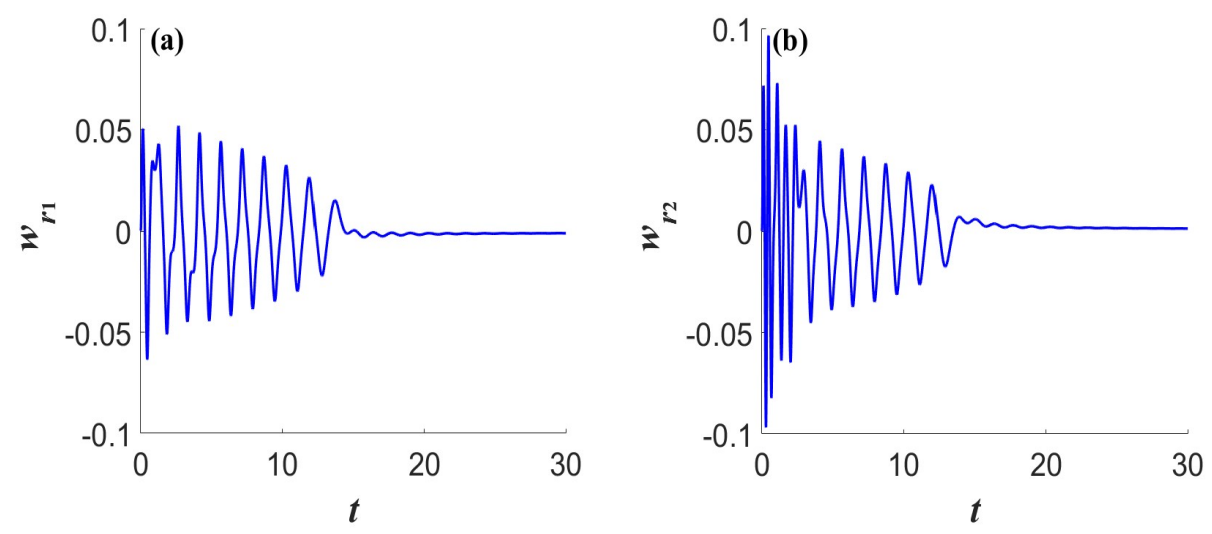


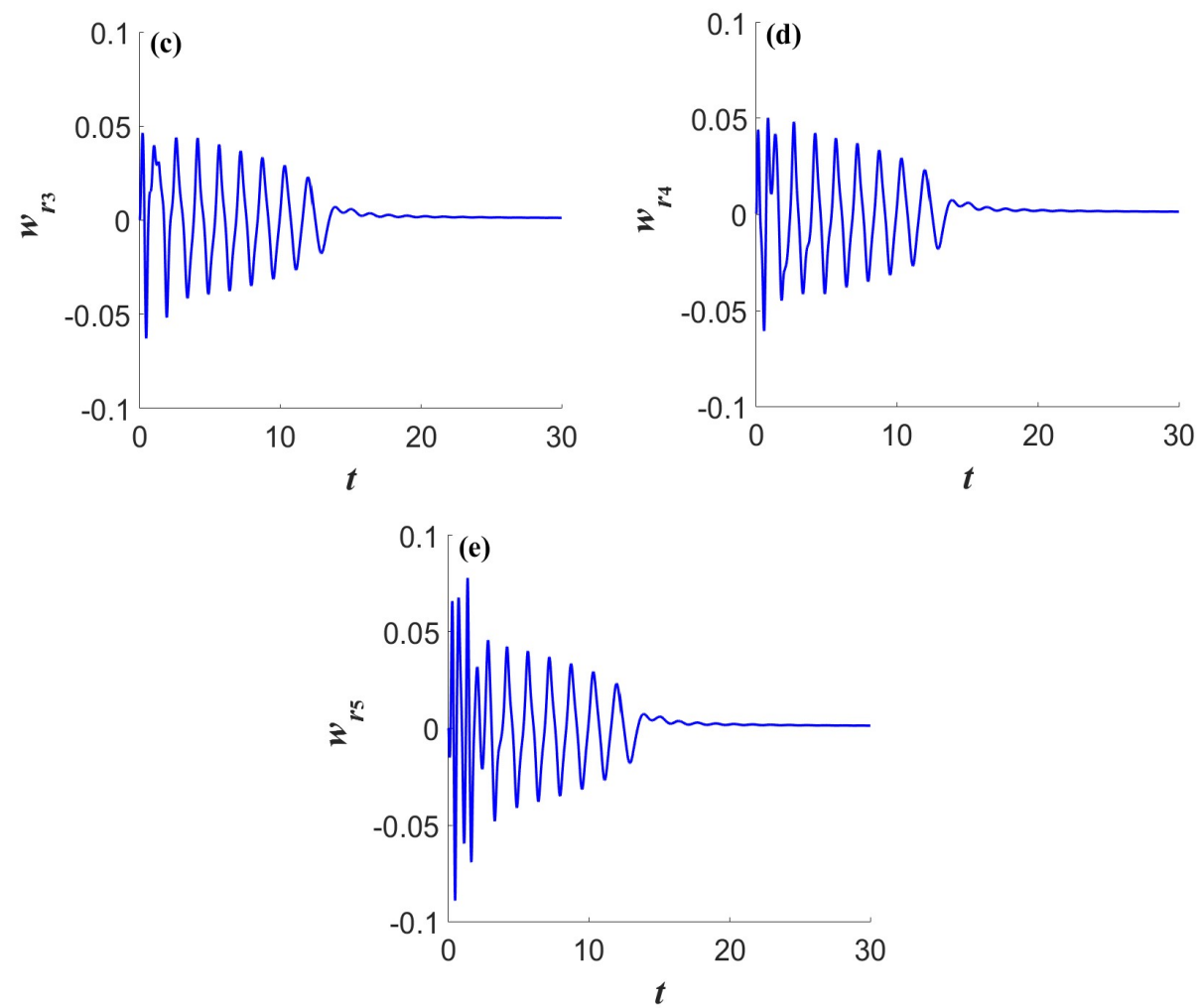

Fig. 6 The relative responses between the plate and the each substructure of five NESs when $f=5$ :

(a) the plate and the $N_{1}$; (b) the plate and the $N_{2}$; (c) the plate and the $N_{3}$; (d) the plate and the $N_{4}$;

(e) the plate and the $N_{5}$
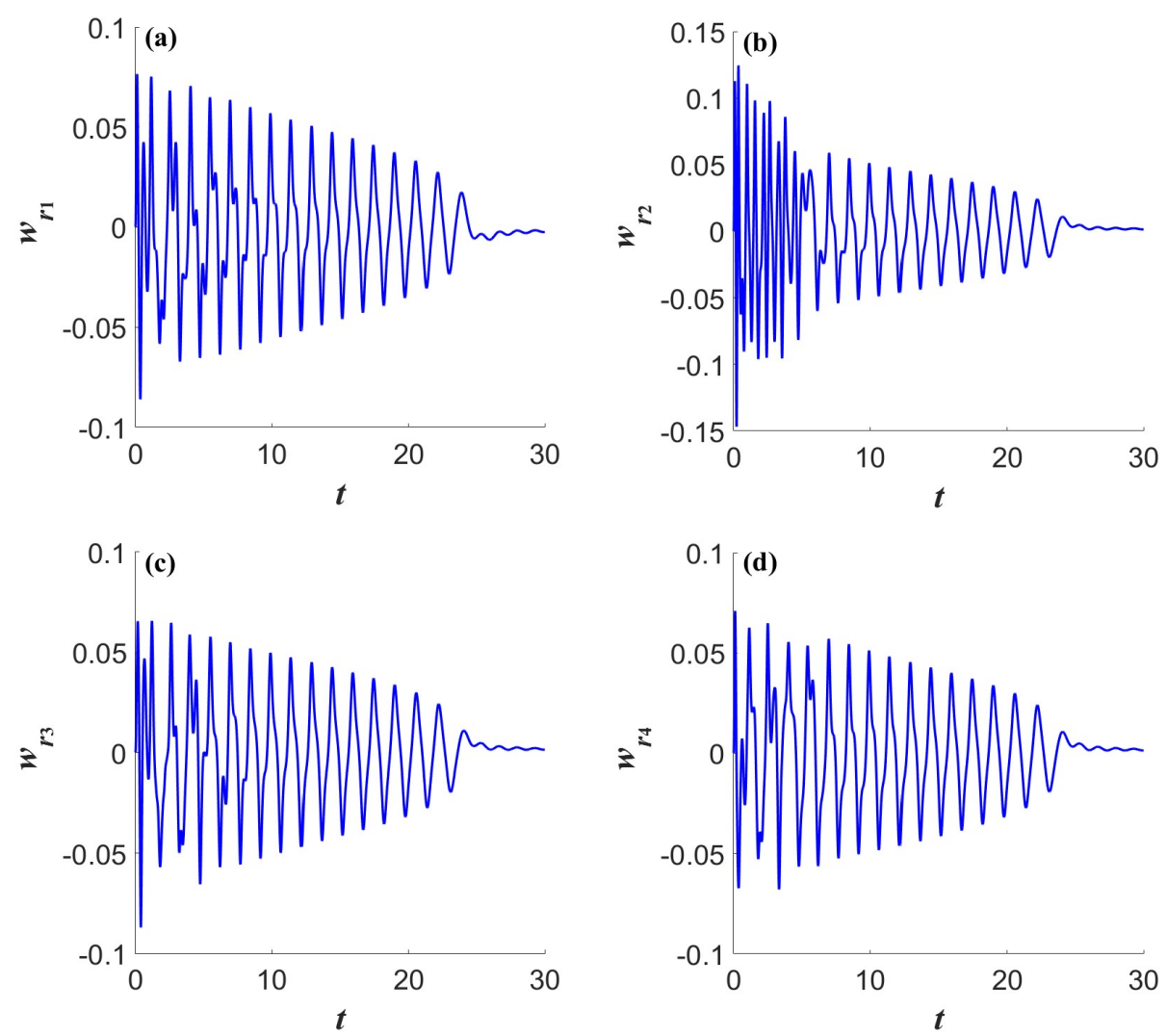


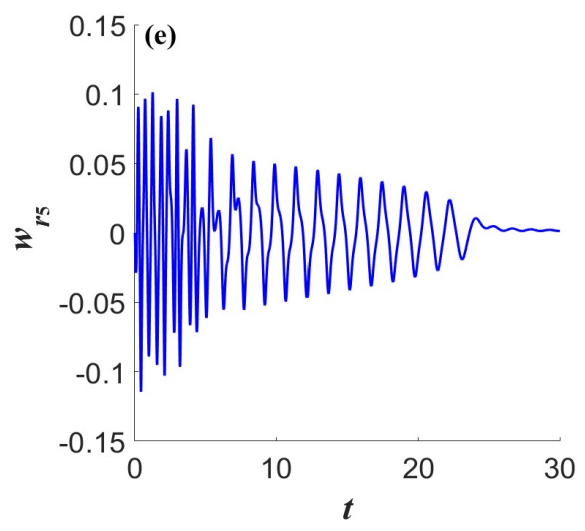

Fig. 7 The relative responses between the plate and the each substructure of five NESs when $f=10$ :

(a) the plate and the $N_{1}$; (b) the plate and the $N_{2}$; (c) the plate and the $N_{3}$; (d) the plate and the $N_{4}$;

(e) the plate and the $N_{5}$

In addition, based on the optimal position, the vibration suppression effects on the transient responses of each mode of the sandwich plate is also investigated. The vibration suppression of the five NESs on the transient response is calculated by the following equation

$$
\eta_{T}=\frac{T-T_{n}}{T} \times 100 \%
$$

where $T$ and $T_{n}$ respectively represent the times for reaching to $5 \%$ of the initial amplitudes of the sandwich plate without and with the five NESs.

Figs. 8, 9 and 10 respectively show the waveforms of the first three transient responses for the sandwich plate without and with five NESs under different excitation amplitudes. It is clearly found that the sandwich plate with the five NESs can always reduce to the required amplitudes in a short time no matter how large the excitation amplitudes.
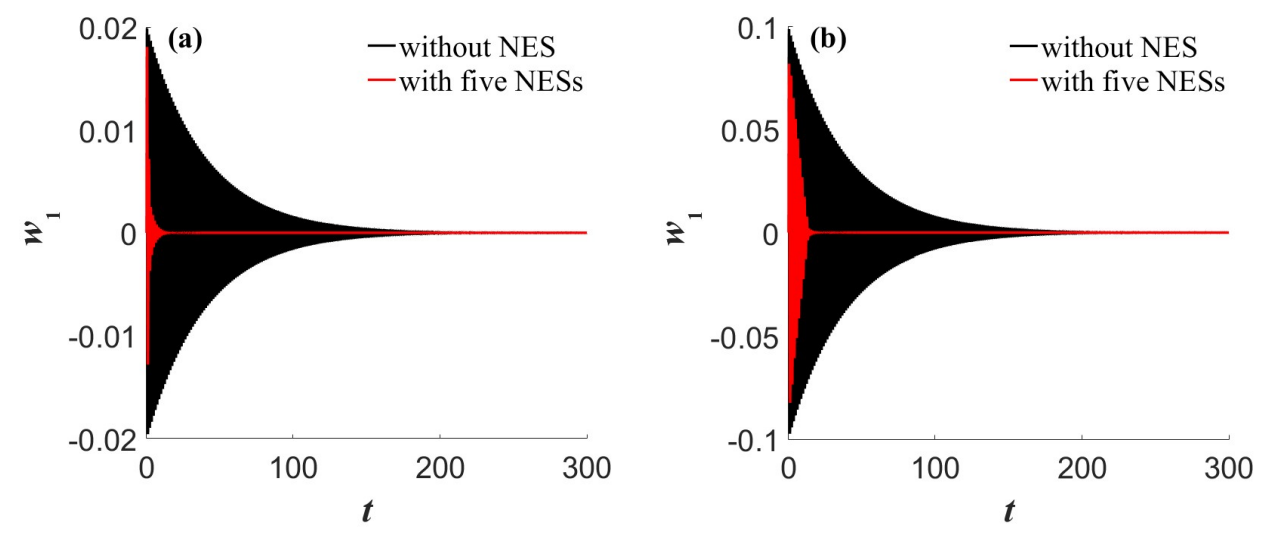


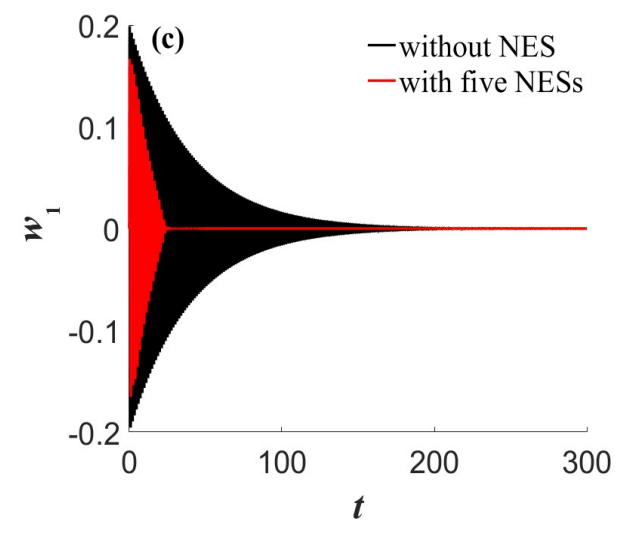

Fig. 8 The first-order transient response of sandwich plate under different excitation amplitudes: (a) $f=1$; (b) $f=5$; (c) $f=10$
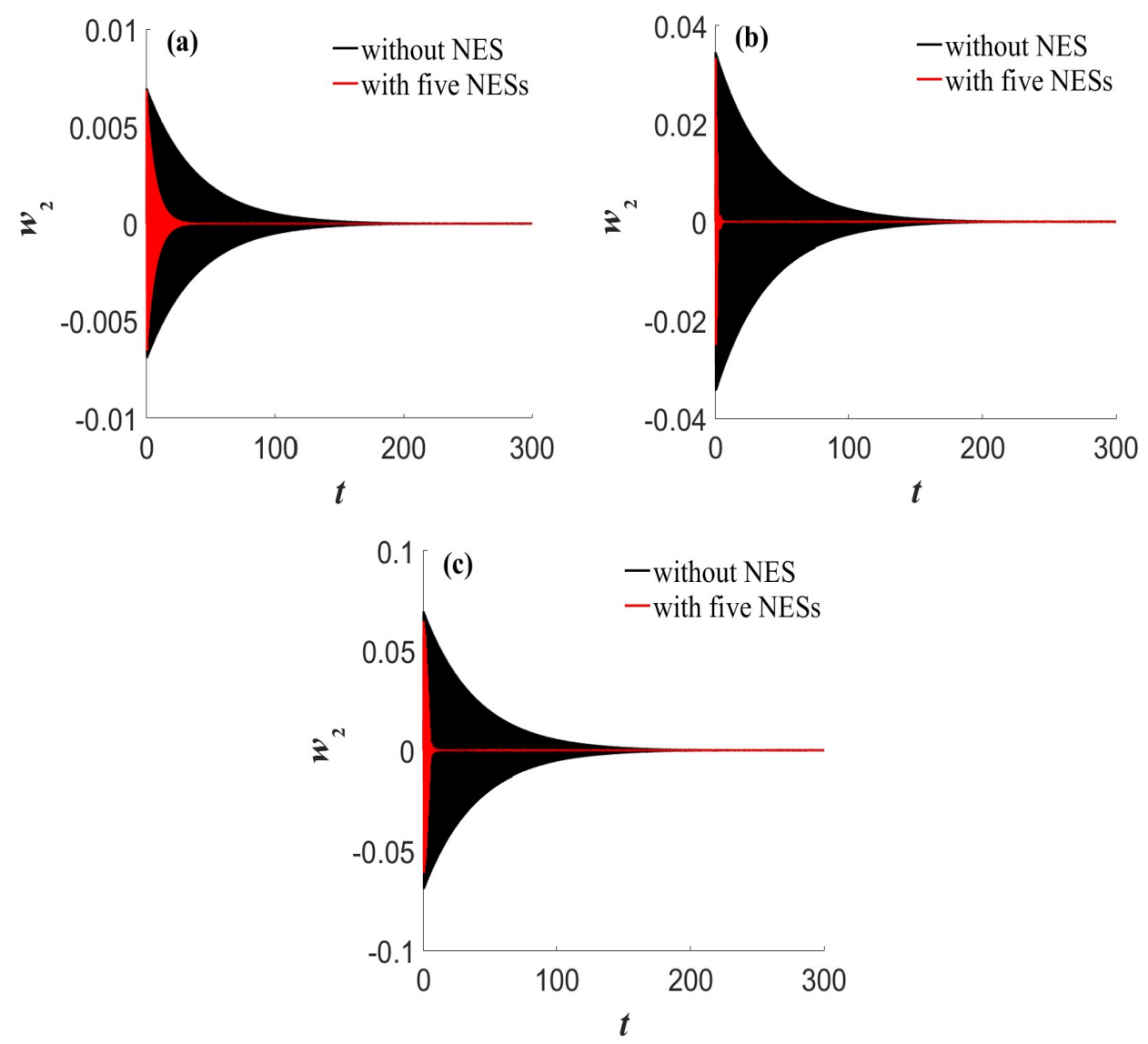

Fig. 9 The second-order transient response of sandwich plate under different excitation amplitudes: (a) $f=1$; (b) $f=5$; (c) $f=10$ 

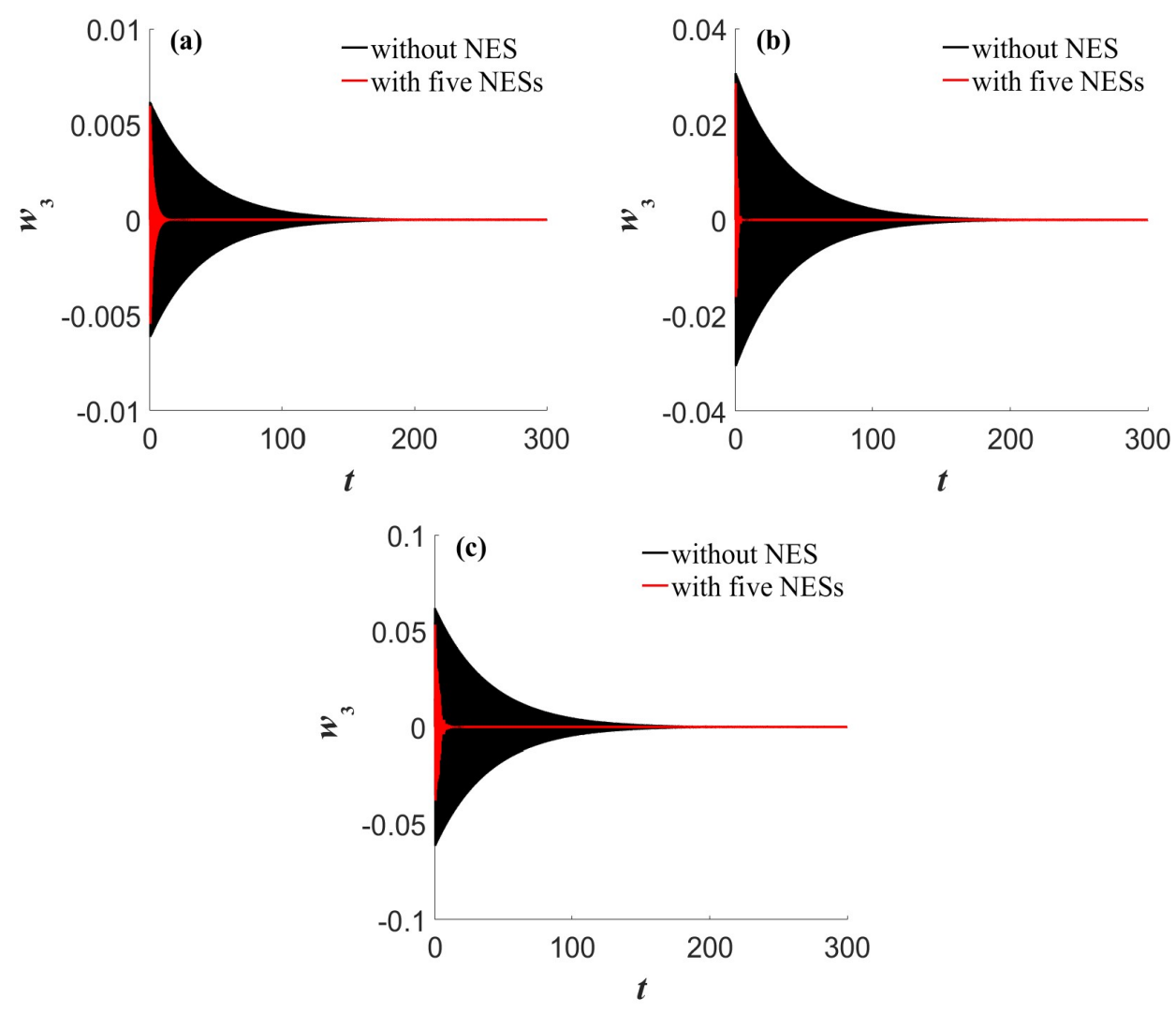

Fig. 10 The third-order transient response of sandwich plate under different excitation amplitudes: (a) $f=1$; (b) $f=5$; (c) $f=10$

Moreover, the specific effects of the five NESs on each mode are calculated by equation 14, and the results are shown in Table 3, which indicts that the vibration suppression of the five NESs gradually decreases on the first-order mode, while the effects on the second and third-order modes increases first and then decreases.

Table 3 Vibration suppression effect of five NES on the first three modes of sandwich plate

\begin{tabular}{llll} 
& $f=1$ & $f=5$ & $f=10$ \\
\hline The first-order & $94.8 \%$ & $89.4 \%$ & $81.1 \%$ \\
The second-order & $82.9 \%$ & $97.5 \%$ & $94.0 \%$ \\
The third-order & $92.9 \%$ & $97.3 \%$ & $94.2 \%$ \\
\hline
\end{tabular}

\subsection{Comparison of single NES and five NESs}

In this part, the performance of the five NESs in the optimal vibration suppression area is compared with that of a single NES. Firstly, the optimal suppression position for the single NES is obtained by successively locating it in the different unit of the sandwich plate, and the energy dissipation ratios of the single NES are obtained with different excitation amplitudes in Fig. 11. 

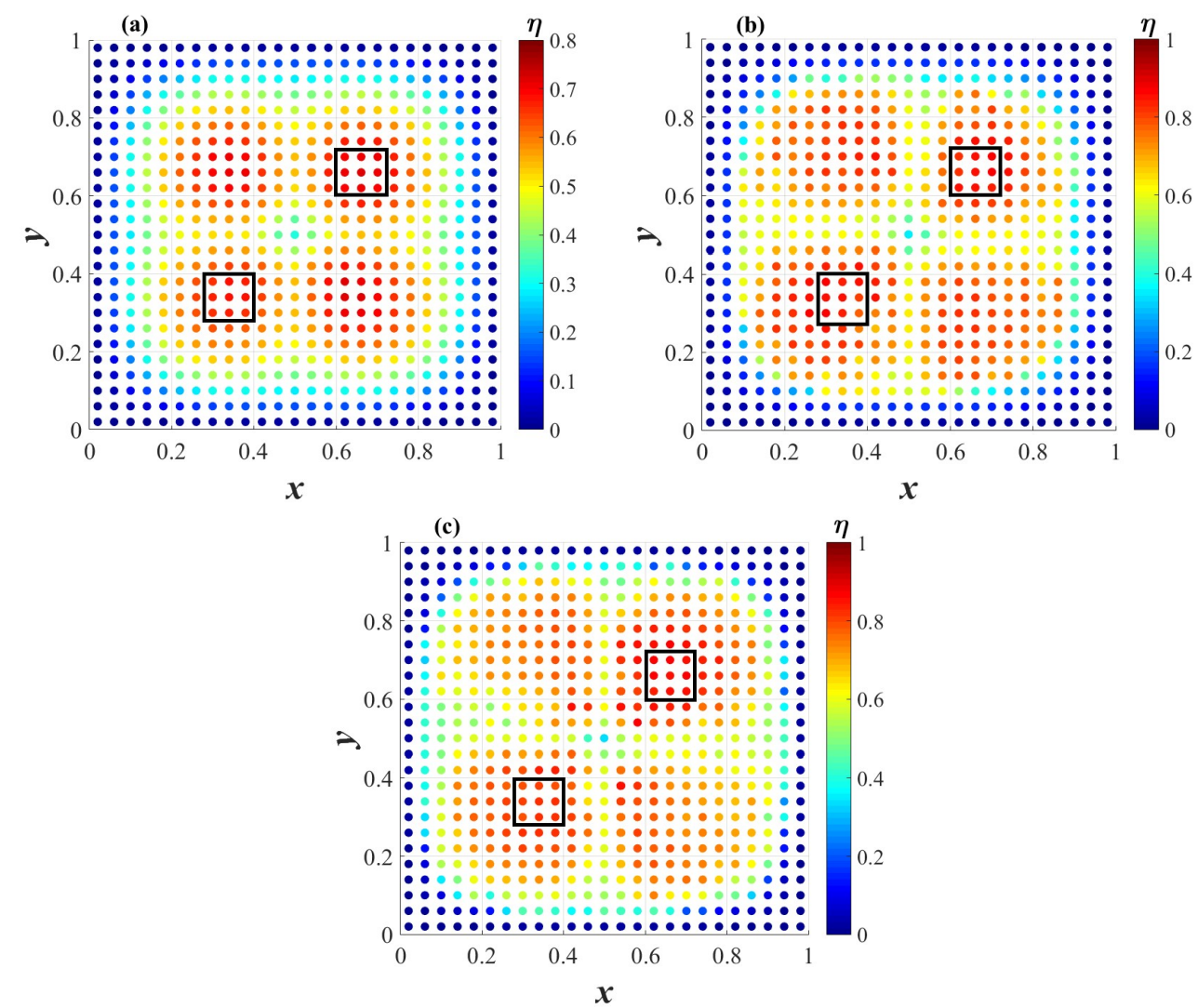

Fig. 11 The energy dissipation ratios of single NES at different positions under different excitation amplitudes: (a) $f=1$; (b) $f=3$; (c) $f=5$

Different from the five NESs, the optimal position for the single NES are not similar with each other when the amplitude of excitation varies. Only some units can be identified, such as the ones surrounded by black boxes in Fig. 11, which are located in

$$
\begin{aligned}
& \mathrm{S}_{1}{ }_{1}=\{(0.28,0.28),(0.40,0.28),(0.28,0.40),(0.40,0.40)\} ; \\
& \mathrm{S}_{2}=\{(0.60,0.60),(0.72,0.60),(0.60,0.72),(0.72,0.72)\} ;
\end{aligned}
$$

To obtain the better comparison, the optimal position for the single NES are chosen as $(0.34,0.34)$ in the following analysis.

Suppose both of the single NES and five NESs be in the optimal position, then, the efficiency of the five NESs with different mass ratios are compared with that of the single NES in the same condition. Fig. 12 gives the energy dissipation ratios of the single and five NESs with the same shock, where $\varepsilon_{t}$ means the total mass ratios of the five NESs. Through the trajectories of different color curves, it can see that the same trend of vibration reduction exists for the five NESs, that is, no matter how the total mass ratio changes, the efficiency of the five NESs declines first then increases later when the excitation amplitude increases to a certain threshold. The efficiency of the absorption can be improved a lot by increasing the mass of the five NESs until $\varepsilon_{t}$ 
equals to 0.06. Moreover, the five NESs have the better suppression than the single NES with the same mass. It still can dominate in the most of the amplitude range when the mass ration of the five NESs reduces to 0.04. Even the ration decreases to 0.02 , there also exists an small advantage area for the five NESs from $f=0.1$ to $f=1.3$.

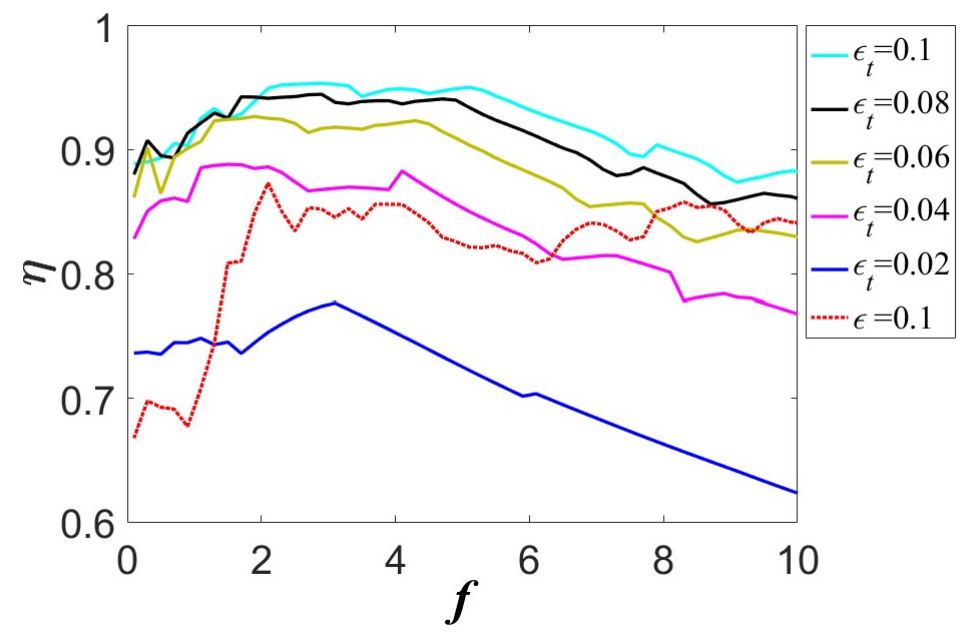

Fig. 12 The energy dissipation ratios of single NES and five NESs with shock amplitude (the solid line represents the five NESs, the dashed line represents the single NES)

\subsection{The effect of five NESs parameters}

The aim of this paper is to obtain the optimal vibration reduction of the five NESs with the minimum mass, so $\varepsilon_{t}$ is chosen as 0.04 for the following parameter optimization based on the Fig 12. The amplitude of the shock force is set as $f=5$ and the parameters of the five NESs keep the same as Fig. 3. Fig. 13 shows the effects of nonlinear stiffness of the NESs on the vibration absorption, which indicts that with the increase of nonlinear stiffness, the suppression of the five NESs increase firstly and decrease later. The effects of the damping of the five NESs on the vibration absorption are consistent with that of the stiffness, as shown in Fig. 14.

The discrepancy of the center one and the other four NESs are also considered. Let the mass ratio of $N_{1}$ be $\varepsilon_{1}$, the ratios of the other four NESs $\left(N_{n, n}=2,3,4,5\right)$ are the same as $\left(\varepsilon_{t}-\varepsilon_{1}\right) / 4$. Then, set $f=5, \gamma_{i}=0.05, k_{i}=800$ and the effects of mass distribution $N_{1}$ on the efficiency of the NESs system are shown in Fig. 15. Choose the total mass ratios be $0.02,0.04,0.06,0.08$ and 0.1 , respectively and different curve colors can describe the mass rations from small to large as blue, red, green, black and cyan. The $x$-axis represents the mass ratio of $N_{1}$ to the sandwich plate, the $y$-axis gives the total mass ratio of the five NESs to the plate, and the $z$-axis is the efficiency of the 
five NESs. It can be found that the overall efficiency of the five NESs is better with smaller $N_{1}$ and larger $N_{n}(n=2,3,4,5)$.

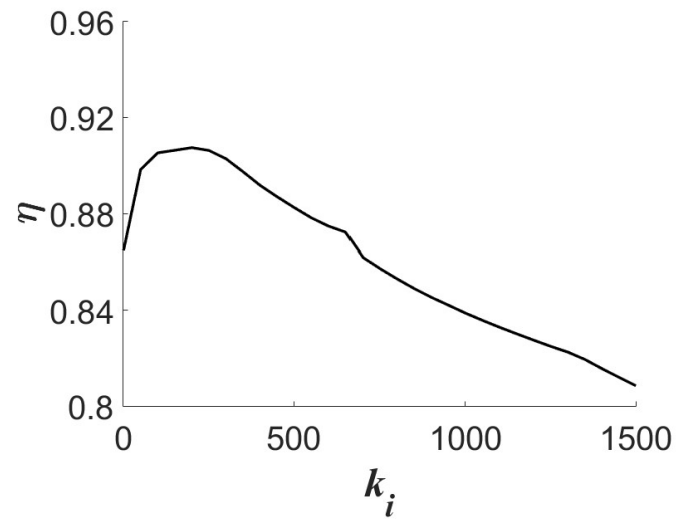

Fig. 13 The variation of efficiency of the five NESs with nonlinear stiffness

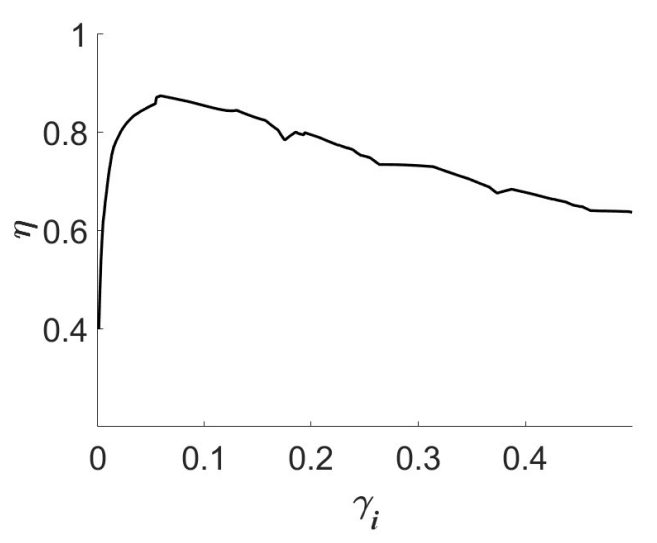

Fig. 14 The variation of efficiency of the five NESs with damping

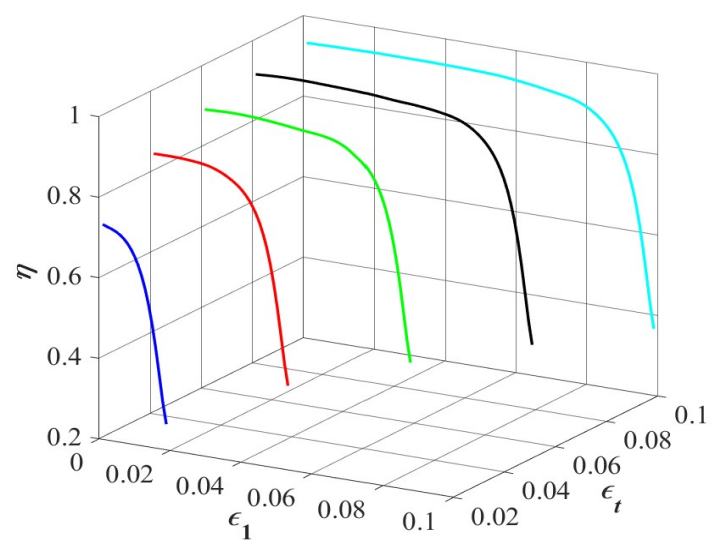

Fig. 15 The variation of efficiency of the five NESs with the mass ratio of $N_{1}$

Moreover, the influence of the damping and stiffness of $N_{1}$ on the efficiency of the five NESs are also discussed. The stiffness and damping of $N_{1}$ are expressed as $k_{1}$ and $\gamma_{1}$, and the same parameters of the other four NESs are written as $\left(k_{t}-k_{1}\right) / 4$ and $\left(\gamma_{t}-\gamma_{1}\right) / 4$, respectively. The total stiffness and damping of the five NESs are chosen as 300, 600, 900, 1200, 1500 and $0.1,0.2,0.3,0.4,0.5$, respectively. Compared the parameters $f=5 、 \varepsilon_{t}=0.04 、 \gamma_{i}=0.05$ with $f=5 、 \varepsilon_{t}=0.04 、 k_{i}=800$, it is found that the effects of stiffness and damping of $N_{1}$ on the overall efficiency are similar as increasing at first and then decreasing with the increased ration of damping and stiffness of $N_{1}$, which are shown in Figs. 16 and 17, respectively. 


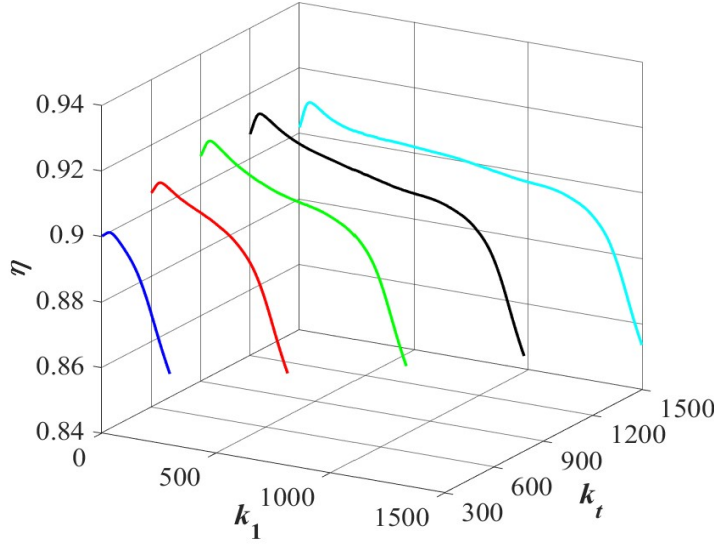

Fig. 16 The variation of efficiency of the five

NESs with the stiffness of $N_{1}$

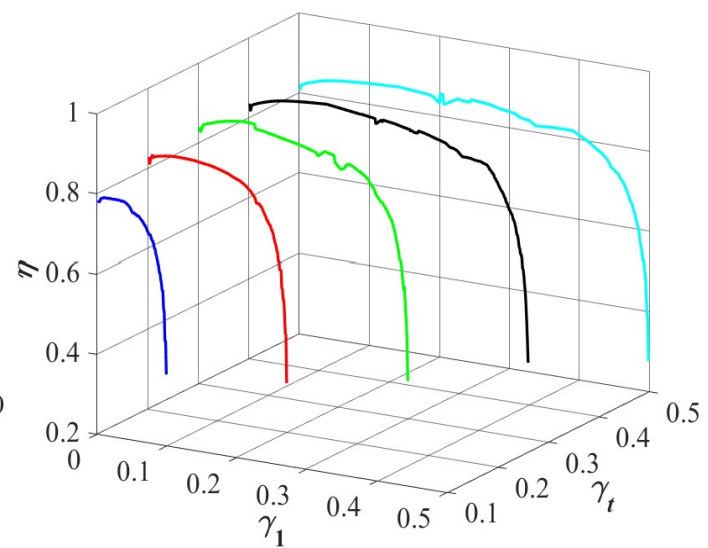

Fig. 17 The variation of efficiency of the five NESs with the damping of $N_{1}$

Finally, the distribution of the five NESs are also analyzed. Name the aforementioned layout way ( $N_{1}$ in the center and the other four around) as case 1. Then, change the position of $N_{1}$ in the optimal position of a single NES as $(0.34,0.34)$ and the other four are layout as case 2 in Fig. 18. By changing the coordinate $\left(a_{2}, b_{2}\right)$ as before, the five NES are distributed at all positions in the sandwich plate. The energy dissipation ratios of the five NESs in case 2 are obtained in Figs. 19(a)、(b) and (c) respectively when $f=1, f=3$ and $f=5$. It is obvious shown that coordinate ( 0.30 , 0.38 ) in black box is also in the optimal vibration suppression position as that in case 1. Therefore, keep $N_{2}$ in $(0.30,0.38)$ in both two cases, then, vibration absorption efficiency of the NESs with excitation amplitude are shown in Fig. 20, which indicts that the varied position of $N_{1}$ can improve the performance of the five NESs, such as $f=0.1 \sim 5.9$.

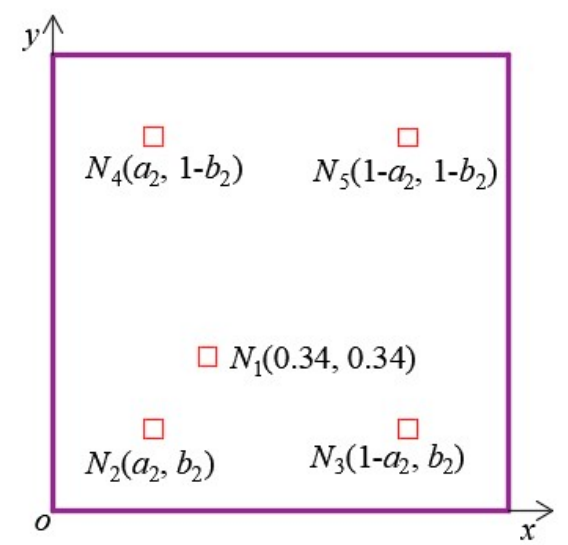

Fig. 18 The layout case 2 of the five NESs 

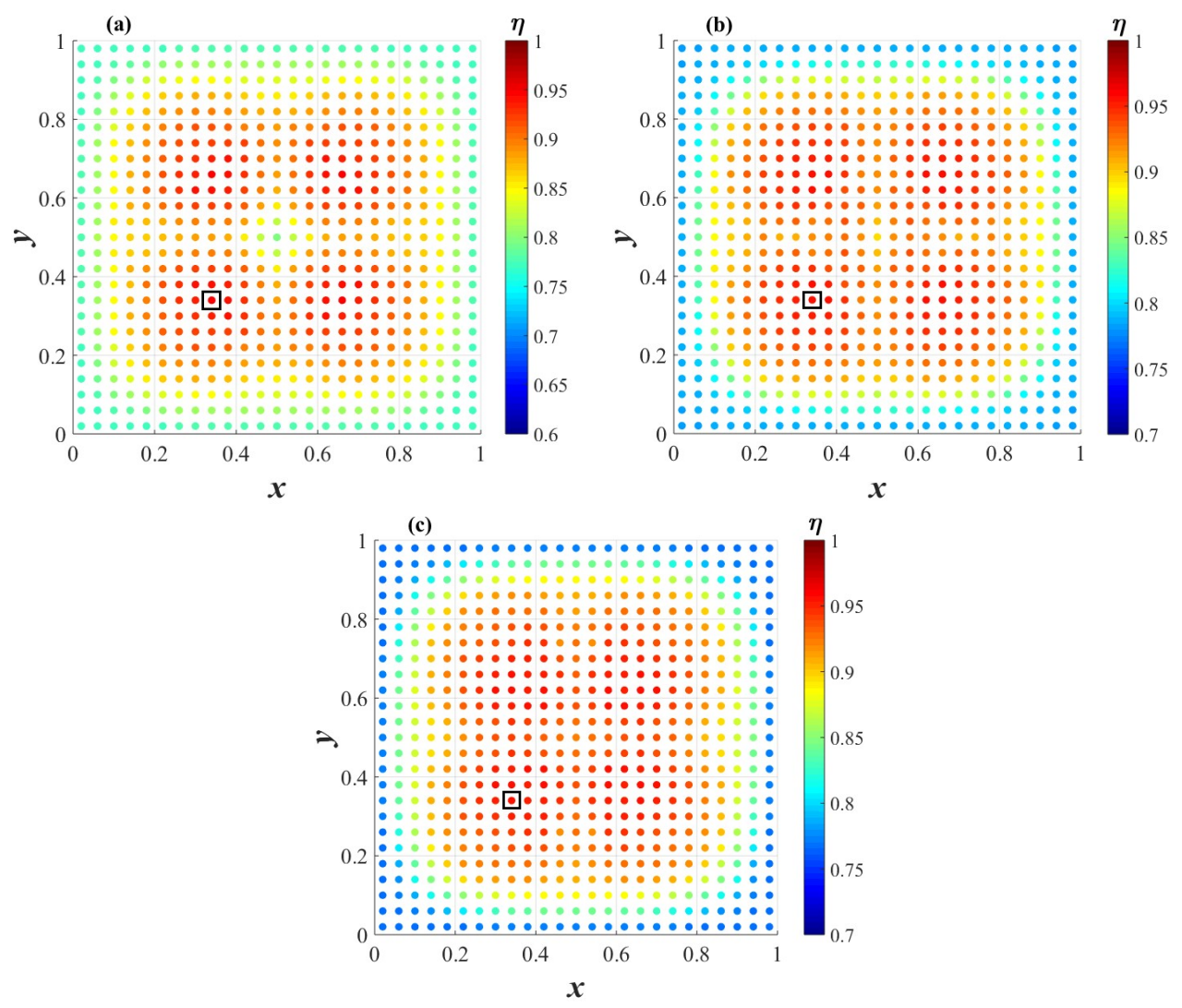

Fig. 19 The energy dissipation ratios of the five NESs at different positions under different excitation amplitudes (case 2): (a) $f=1$; (b) $f=3$; (c) $f=5$;

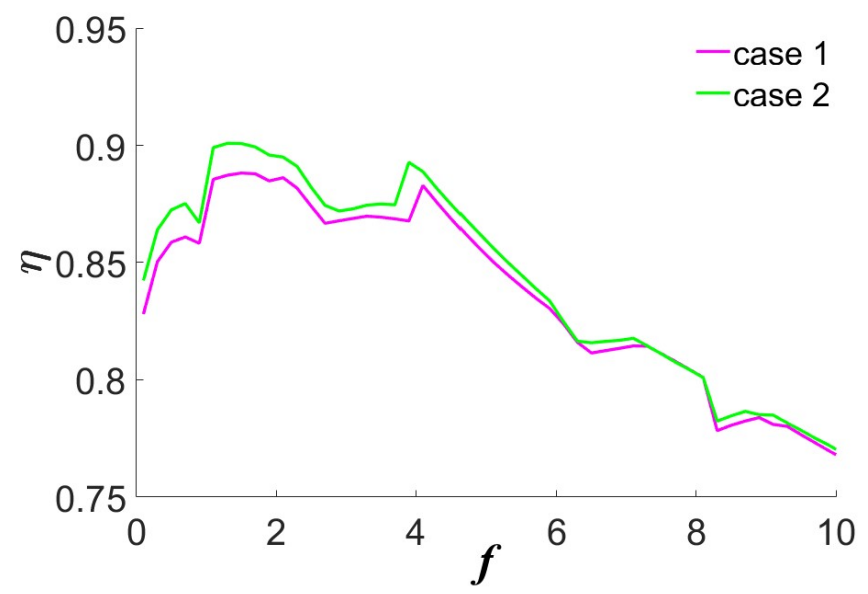

Fig. 20 Comparison of two layout cases under different excitation amplitudes

\section{Conclusions}

In this paper, the vibration absorption of the five NESs on the composite truss core sandwich plate are investigated with shock excitations. The nonlinear dynamical equations of motion for the coupled system are built by the first-order shear 
deformation theory and Galerkin method, and then the vibration control performance of the five NESs are analyzed by numerical methods.

Firstly, the results find that the position distribution of both the five NESs and the shock excitation have a great influence on the vibration suppression, but the excitation amplitudes have little effects on the optimal area for the five NESs. Then, based on the optimal energy absorption area, feasibility of the scheme and the action of five NESs on the first three modes of the sandwich plate are discussed. The performance of the single and the five NESs in the optimal position are compared and the five NESs present the much better suppression than the single one. It is found that for a larger range of excitation amplitudes, the best suppression quality of the five NESs can decrease $60 \%$ compared with the single NES. The smaller the excitation amplitude, the more obvious the quality advantage of the five NESs. Therefore, the reasonable distribution of multi NESs in multi-dimensional space have great values of small total mass and high efficiency in vibration control fields.

In addition, the influence of the parameters on the efficiency of the five NESs are also studied to further improve the vibration suppression. Finally, two different layout ways are selected to discuss the effects of the position $N_{1}$ on the characters of the five NESs, which show that the varied position of $N_{1}$ can improve the performance of the five NESs.

\section{Acknowledgements}

The authors gratefully acknowledge the support of the National Natural Science Foundation of China (NNSFC) through grant Nos.12172014,11772010 and 11832002. Key Laboratory of Vibration and Control of Aero-Propulsion System, Ministry of Education, Northeastern University (VCAME202004).

\section{Conflict of Interest}

The authors declare that they have no conflict of interest with respect to the research, authorship, and/or publication of this article. 


\section{References}

[1]Li XD, Xiong J, Ma L, Wu LZ, Yan XQ. Effect of vacuum thermal cycling on the compression and shear performance of composite sandwich structures containing pyramidal truss cores. Composites Science and Technology. 2018; 158: 67-78.

[2] Qi G, Ma L, Wang SY. Modeling and reliability of insert in composite pyramidal lattice truss core. Composite Structures. 2019; 221: 110888.

[3]Shen C, Xin FX, Lu TJ. Theoretical model for sound transmission through finite sandwich structures with corrugated core. International Journal of Non-Linear Mechanics. 2012; 47: 1066-1072.

[4]Zhang XY, Zhou H, Shi WH, Zeng FM, Zeng HZ. Vibration tests of 3D printed satellite structure made of lattice sandwich panels. AIAA Journal. 2018; 10: 4213-4217.

[5]Zhang W, Wu QL, Yao MH, Dowell EH. Anaysis on global and chaotic dynamics of nonlinear wave equations for truss core sandwich plate. Nonlinear Dynamics. 2018; 94: 21-37.

[6] Wang DW, Ma L, Wang XT, Wen ZH, Glorieux C. Sound transmission loss of laminated composite sandwich structures with pyramidal truss cores. Composite Structures. 2019; 220: 19-30.

[7]Zangana S, Epaarachch S, Ferdous W, Leng JS, Schubel P. Behaviour of continuous fibre composite sandwich core under low-velocity impact. Thin-Walled Structures. 2021; 158: 107157.

[8]Lou J, Wu LZ, Ma L, Xiong J, Wang B. Effects of local damage on vibration characteristics of composite pyramidal truss core sandwich structure. Composites: Part B. 2014; 62:73-87.

[9]Xiong J, Ma L, Pan S, Wu L, Papadopoulos J, Vaziri A. Shear and bending performance of carbon fiber composite sandwich panels with pyramidal truss cores. Acta Materialia. 2012; 60: 1455-1466.

[10] Wang B, Zhang GQ, He QL, Ma L, Wu LZ, Feng JC. Mechanical behavior of carbon fiber reinforced polymer composite sandwich panels with 2-D lattice truss cores. Materials and Design. 2014; 55: 591-596.

[11]Huang W, Fan ZH, Zhang W, Liu JY, Zhou W. Impulsive response of composite sandwich structure with tetrahedral truss core. Composites Science and Technology. 2019; 176: 17-28. 
[12] Yin S, Wu LZ, Yang JS, Ma L, Nutt S. Damping and low-velocity impact behavior of filled composite pyramidal lattice structures. Journal of Composite Materials. 2014; 15: 1789-800.

[13]Zhang GQ, Wang B, Ma L, Wu LZ, Pan SD, Yang JS. Energy absorption and low velocity impact response of polyurethane foam filled pyramidal lattice core sandwich panels. Composite Structures. 2014; 108: 304-310.

[14]Chen K, Neugebauer A, Goutierre T, Tang A, Glicksman L, Gibson LJ. Mechanical and thermal performance of aerogel-filled sandwich panels for building insulation. Energy and Buildings. 2014; 76: 336-346.

[15]Li FM, Lyu XX. Active vibration control of lattice sandwich beams using the piezoelectric actuator/sensor pairs. Composites: Part B. 2014; 67: 571-578.

[16]Song ZG, Li FM. Aeroelastic analysis and active flutter control of nonlinear lattice sandwich beams. Nonlinear Dynamics. 2014; 76: 57-68.

[17]Chai YY, Li FM, Song ZG, Zhang CZ. Analysis and active control of nonlinear vibration of composite lattice sandwich plates. Nonlinear Dynamics. 2020; 102: 2179-2203.

[18]Gourdon E, Lamarque CH. Nonlinear energy sink with uncertain parameters. Journal of Computational and Nonlinear Dynamics. 2006; 1: 187-195.

[19]Vakakis AF. Inducing passive nonlinear energy sinks in vibrating systems. Journal of Vibration and Acoustics. 2001; 123: 324-332.

[20]Tripathi A, Grover P, Kalmár-Nagy T. On optimal performance of nonlinear energy sinks in multiple-degree-of-freedom systems. Journal of Sound and Vibration. 2017; 388: 272-297.

[21]Georgiades F, Vakakis AF. Dynamics of a linear beam with an attached local nonlinear energy sink. Communications in Nonlinear Science and Numerical Simulation. 2007; 12: 643-651.

[22]Lu Z, Wang ZX, Zhou Y, Lu XL. Nonlinear dissipative devices in structural vibration control: A review. Journal of Sound and Vibration. 2018; 423: 18-49.

[23]Moslemi A, Khadem SE, Khazaee M, Davarpanah A. Nonlinear vibration and dynamic stability analysis of an axially moving beam with a nonlinear energy sink. Nonlinear Dynamics. 2021; 404: 1955-1972.

[24]Liu Y, Chen GP, Tan X. Dynamic analysis of the nonlinear energy sink with local and global potentials: geometrically nonlinear damping. Nonlinear Dynamics. 2020; 101: 2157-2180. 
[25]Taghipour J, Dardel M. Steady state dynamics and robustness of a harmonically excited essentially nonlinear oscillator coupled with a two-DOF nonlinear energy sink. Mechanical Systems and Signal Processing. 2015; 62-63: 164-182.

[26]Fang X, Wen JH, Yin JF, Yu DL. Highly efficient continuous bistable nonlinear energy sink composed of a cantilever beam with partial constrained layer damping. Nonlinear Dynamics. 2017; 87:2677-2695

[27]Zang J, Yuan TC, Lu ZQ, Zhang YW, Ding H, Chen LQ. A lever-type nonlinear energy sink. Journal of Sound and Vibration. 2018; 437: 119-134.

[28]Chen JE, He W, Zhang W, Yao MH. Liu J, Sun M. Vibration suppression and higher branch responses of beam with parallel nonlinear energy sinks. Nonlinear Dynamics. 2018; 91: 885-904;

[29]Tian W, Li YM, Li P, Yang ZC, Zhao T. Passive control of nonlinear aeroelasticity in hypersonic 3-Dwing with a nonlinear energy sink. Journal of Sound and Vibration. 2019; 462: 114942.

[30]Li WK, Wierschem NE, Li XH, Yang TJ, Brennan MJ. Numerical study of a symmetric single-sided vibro-impact nonlinear energy sink for rapid response reduction of a cantilever beam. Nonlinear Dynamics. 2020; 100: 951-971.

[31]Zhang YW, Zhang H, Hou S, Xu KF, Chen LQ. Vibration suppression of composite laminated plate with nonlinear energy sink. Acta Astronautica. 2016; 123: 109-115.

[32]Yao HL, Cao YB, Ding ZY, Wen BC. Using grounded nonlinear energy sinks to suppress lateral vibration in rotor systems. Mechanical Systems and Signal Processing. 2019; 124: 237-253.

[33]Zhang YW, Zhang Z, Chen LQ, Yang TZ, Fang B, Zang J. Impulse-induced vibration suppression of an axially moving beam with parallel nonlinear energy sinks. Nonlinear Dynamics. 2015; 82: 61-71.

[34]Zhang YW, Yuan B, Fang B, Chen LQ. Reducing thermal shock-induced vibration of an axially moving beam via a nonlinear energy sink. Nonlinear Dynamics. 2017; 87: 1159-1167.

[35]Allen HG. Analysis and design of structural sandwich panels. Oxford: Pergamon Press; 1969.

[36]Chen JE, Zhang W, Sun M, Yao MH, Liu jun. Free vibration analysis of composite sandwich plates with different truss cores. Mechanics of Advanced Materials and Structures. 2018; 25: 9701-9713. 



\section{Supplementary Files}

This is a list of supplementary files associated with this preprint. Click to download.

- DataAvailabilityStatements.docx 